\title{
Resource Creation for Automatic Translation System from Texts in Spanish into Mexican Sign Language
}

\author{
Obdulia Pichardo-Lagunas, Bella Martinez-Seis \\ Instituto Politécnico Nacional, Interdisciplinary Professional Unit on Engineering and \\ Advanced Technologies (UPIITA), México DF, \\ Mexico \\ opichardol@ipn.mx
}

\begin{abstract}
Mexican Sign Language (LSM) has been recognized as part of the official cultural background of Mexico since 2005. However, nowadays there is no federal program that considers the creation of lexical resources for LSM, standardization of its syntactic rules and unification of its vocabulary. It is important to mention that LSM is an agraphic language, i.e., it has no writing system. On the other hand, computing sciences face an important challenge regarding the creation of digital resources for specific text processing tasks. This paper describes the creation of linguistic resources that are necessary in the automatic translation from written Spanish into LSM. We also present an approach that we use for automatic translation from written Spanish into LSM and the system, which implements it.
\end{abstract}

Keywords: Mexican Sign Language (LSM), automatic translation, natural language processing, LSM dictionary.

\section{Introduction}

According to Mexican National Institute of Geography and Statistics (INEGI) official numbers, there are 5,739,270 persons, i.e., around 5.1\% of the Mexican population, that are disabled for hearing to some extent, and 694,270 of these have hearing impairment.

Persons with hearing impairment can be classified into three categories: first, persons having this deficiency since they were born, next, there are persons who could hear normally, but they lost this ability in an accident or a disease, and, finally, those who lose gradually the hearing by aging.

Again according to the INEGI information in 2006, $60 \%$ of deaf persons in Mexico can use Mexican Sign Language (LSM, lenguaje de señas mexicano), out of these just $20 \%$ can read and write in Spanish. Deaf persons, who can read and write in Spanish, use a variation of the LSM, in which they try to follow the correct grammar rules. This language is called Signed Spanish. There are only few cases when persons who can hear perfectly seek to learn sign language. 
The main purpose of our work is to develop a tool that simplifies the communication between persons who can read and write Spanish and deaf persons who understand and use the LSM.

\section{Theoretical Framework}

In this section we describe the antecedents and the essential features of the Sign Languages (LS, lenguajes de señas), as well as the general concepts regarding the automatic translation and the translation process as such.

\subsection{Sign Languages}

Sign language is the natural language for deaf persons and like all languages it emerges from the necessity to establish communication between persons. LS is threedimensional and agraphic language [1].

Sign languages have their own rules, they are not a copy of the oral languages nor their representation, although the influence of the dominant spoken language is undeniable.

Deaf persons are born with the biological capability for learning a language, however, their hearing impairment impedes to acquire the oral language spoken around them.

Unlike oral languages, the sign language focuses its operation on the visual perception, while oral languages are based on the auditory perception. The key differences between spoken languages and sign languages are shown in Table 1 [2].

Table 1. Differences between spoken and sign languages.

\begin{tabular}{|l|l|}
\hline Oral languages & Sign languages \\
\hline Auditory attention & Visual attention \\
\hline Auditive memory & Visual memory \\
\hline Linear space & Three-dimensional space \\
\hline Vocal emission & Body-space transmission \\
\hline Sequentiality & Simultaneity \\
\hline
\end{tabular}

There are significant geographical variations of LSM in Mexico. There are variants in Mexican northern regions, where the LSM is influenced by the ASL (American Sign Language). Southern states have their own variant. Finally, there is an alternative sign language in the state of Yucatán.

The lack of a writing system leads to a general lack of historical (written) documents, which would allow the study of grammar of the language in its evolution.

\subsection{Automatic Translation}

Automatic translation is the process when a computer application converts a natural language text written in any language (source) into another language (destination). The 
main goal of the translation techniques is to "catch" the meaning in the original text and to transmit it as a full coherent text in another language.

The evolution of the automatic translation studies shows two leading standpoints: translation based on rules and translation based on a corpus.

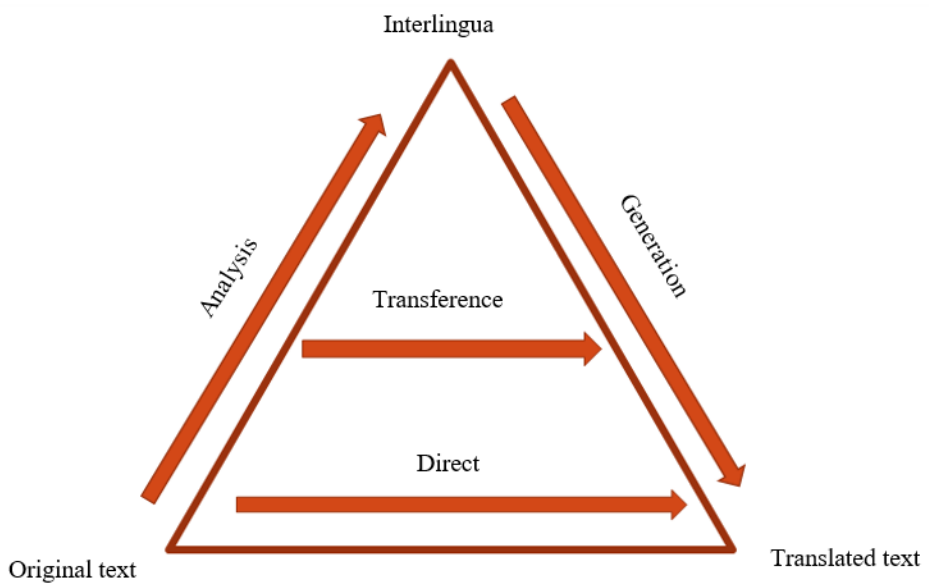

Fig. 1. Bernard Vauquois’ pyramid. Interlingual Machine Translation.

The corpus based translation uses statistical techniques to make the translation as accurate as possible, using previously translated texts as the basis. This type of translation provides high quality, when there are available very large monolingual and bilingual corpora that allow construction of the statistical models of translation.

The purpose of the rule-based translation is to achieve semantic equivalences based on concepts of generative linguistics and artificial intelligence by using dictionaries and a wide-range set of linguistic rules that identify the elements which represent a whole language. Usually, tree structures are used to represent structure of sentences.

General scheme of the automatic translation is presented in Fig. 1. There are three possibilities: direct translation, transference rules, and interlingua, when the phrases are translated first into an intermediate language and then the output is generated.

The direct method is the simplest method, which usually obtains poor results. A minimum analysis is done, syntactic analysis is omitted. The translation is made word by word and lacks of any intermediary stage.

The indirect method obtains a representation of the source text, from which the target text is generated. Indirect methods are divided into two categories: interlingua based methods and transfer methods.

Interlingua performs the translation in two stages using a universal intermediate representation. The first stage involves an analysis of the text in the source language, whose result is an abstract semantic representation, also called interlingua. The second phase establishes the relationship between the interlingua and the output text, i.e., the translation is created from the interlingua. Regarding this technique, the representation between languages is neutral, so it works for any language pairs. 
Transfer technique suggests two intermediate representations, one for each language of the translation being at the same time dependent on the used languages.

The execution of this method implies the creation of three modules for each language:

- The analysis module, which obtains lexical, syntactic and semantic representation.

- The transfer module, which creates equivalences between the representations of the languages.

- The generation module, which starts working after the transfer module. The text itself is generated for the specific target language.

The transference is done at three levels:

- Lexical transfer, finding the corresponding terms in the target language, is performed using dictionaries.

- Syntactic transfer, when the parsed tree of the source language sentence is transformed into an equivalent tree of the target sentence.

- Semantic transfer, when deep representations are transformed as patterns of diverse cases, semantic networks or logical structures.

\section{$3 \quad$ Related Work}

In this section, we describe the work related to the automatic translation between the written Spanish and the sign languages (for various natural languages). The Mexican Sign Language (LSM) has different characteristics as compared to those used in other countries, so, the state of the art techniques described below should be adjusted and adapted.

\subsection{TextoSIGN: Text Conversion into a Sign Language}

TextoSIGN system for text conversion into a sign language [8] is developed by the Technological Institute of Castilla and Leon and XUL Social Media Company in 2011. The system is able to show the requested sentences by using sign language. It contains 350 signs. The signs or words that are not in this list are spelled.

The translator essentially permits two different uses: the export of the phrases into a video format sentences in order to be loaded on any web page or the real time visualization as a training tool, which allows to see the translator from any position while learning the execution of different signs.

\subsection{CONSIGNOS: Converter and Automatic Statements of Sign Language}

The system CONSIGNOS [9] was developed in 2008 in the Polytechnic University of Madrid and the University of Castilla L. The system uses the following techniques: 
Resource Creation for Automatic Translation System from Texts in Spanish into Mexican Sign ...

- Automatic speech recognition based on Hidden Markov Models, combined with statistical language models using lists of examples.

- Syntactic and semantic rules.

- Statistical algorithms based on subsequences of phrases and finite-state transducers.

- Algorithms of integration of different translation strategies.

- Nonlinear animation techniques for the independent actions arrangement.

- Description of the actions in an independent matter.

- Description of actions independently of the avatar using descriptors based on quaternions and methods of inverse kinematics.

- Mesh deformation methods (Vertex Blending).

- Generation of realistic representation output as a black box for the other modules.

- Transparent incorporation of distributed realistic synthesis based on the GRID.

\subsection{Natural Language Translation System into Spanish Sign Language}

Natural Language Translation System into Spanish Sign Language [10] was developed in 2012 by Colas-Pasamontes and Lopez-Colino from the Autonomous University of Madrid. It is based on two modules: the translator and the sign language synthesizer. The translator was designed as generic and independent from the context. This element makes use of grammatical and syntactic analysis systems including a set of over 75,000 words in Spanish. The sign language synthesizer utilizes a design based on philological studies applied to the Spanish Sign Language. In addition, the graphic library JSR-184 is used.

\subsection{Online Signs Languages Translator}

Online Signs Languages Translator [11] was developed in 2012 by Leal Rodriguez. It uses a vocabulary and a set of grammar rules for translation. The system states that the sign language has the following linguistic peculiarity: using a single sign, it is possible to display an entire sentence. The system (1) reads the sentence, (2) labels it, (3) breaks the phrase into proper grammar rules, (4) finds in the database the required words, (5) searches in the database the existence of any combination of words that can be expressed in a single sign, and (6) the words that are not found are spelled using signs. Once this procedure is finished, the written phrase is translated into a sequence of signs that is displayed image by image.

\section{Methodology for Creation of the Dictionary}

We had the assistance of the Integral Attention Center for disabled persons of the Cuauhtémoc District in Mexico City. We recorded 1,790 signs in a JPEG format 10 frames per second. The words were extracted from the dictionary "Manos con voz" ("Hands with voice") [4] and "Mis manos que hablan" ("My hands speak") [5]. We 
also added words using vocabulary for the signs of the Mexican northern, center and southern areas, with the collaboration of Seña y Verbo Association.

A corpus that contains one hundred sentences in Spanish was developed. These sentences were mapped taking into account the Spanish sign language grammar structure. The corpus is useful for analysis of the grammatical relations between both languages. This mapping is the first experience in the field. It was validated using the proper syntactic structures, mentioned in Gramática de la Lengua de Señas Mexicana [7]. The examples of translated sentences are presented in Fig. 2.

$\begin{array}{lll}\text { La casa es bonita } & \text { casa bonita } & \text { The house is pretty } \\ \text { Yo trabajé mucho } & \text { Yo ya trabajar mucho } & \text { I worked hard } \\ \text { Yo tengo hambre } & \text { Hambre } & \text { I am hungry }\end{array}$

Fig. 2. Example of translated sentences.

The labeled sentences correspond to previously established grammar rules. Besides, they represent the simplest structures in Spanish. All these sentence structures are listed below:

1. Art- Noun -Verb- Adj

2. Art- Noun - Verb- Adv

3. Art- Noun - Verb- Noun

4. Art- Noun - Verb- Art- Noun

5. Art- Noun- Verb- Adv- Adj

6. Art- Noun - Verb- Adv- Prep- Art- Noun

7. Art- Noun - Verb- Prep- Art- Noun

8. Art- Noun - Verb- Art- Noun - Prep- Art- Noun

9. Art- Noun - Verb- Adv- Prep- Art- Noun - Prep- Art- Noun

10. Art- Noun - Conj- Art- Noun- Verb- Prep- Art- Noun

11. Art- Noun - Conj- Art- Noun- Verb- Adv- Prep- Art- Noun

12. Art- Noun - Conj- Art- Noun- Verb- Adj

13. Art- Noun - Prep- Art- Noun- Verb- Adj

The developed resource can be used in making of the automatic translation, which has the following features:

- The translation is held in a single direction, from the written Spanish to the LSM.

- There is a restricted vocabulary related to the home environment only.

- A limited group of grammatical structures is used. 
The system overview is presented in Fig. 3. To achieve the translation, the system takes the text in the source language and processes it using Freeling [3]. Having identified the elements of the sentence, there is a verification whether the words are part of the defined vocabulary or not. For the moment, the system only translates using the specified vocabulary and the unknown words are not spelled. Still, if we would like the system to work at the full scale, a deaf person would need to know how to spell the unknown words.

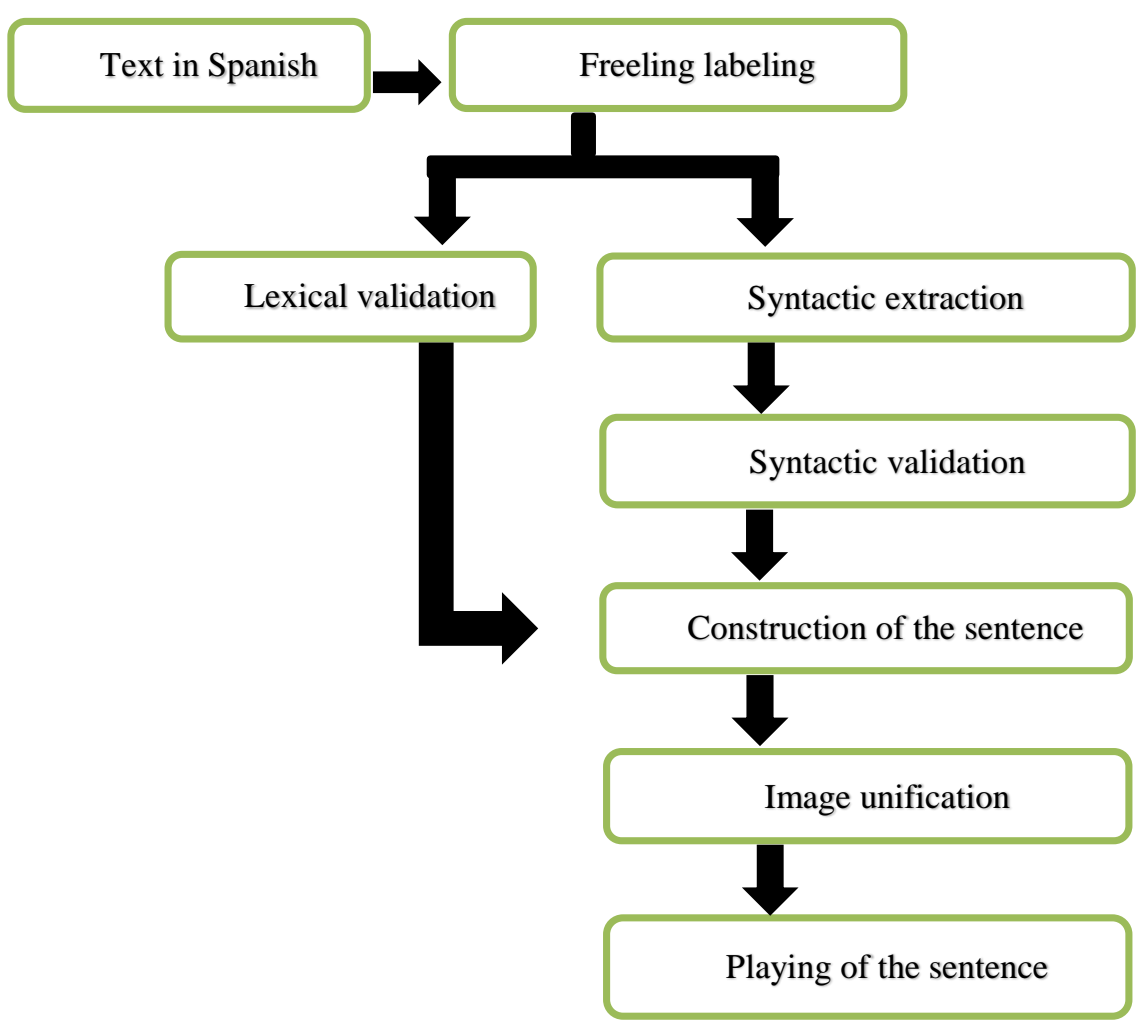

Fig. 3. System overview.

Once the vocabulary is authenticated, the syntactic structure as an outcome during the labeling step is checked out, so that the correspondent syntactic item is found in the database and is matched. If the grammar structure is included in the database, it is mapped with the equivalent structure in the LSM.

When the grammar is verified and identified, the system seeks in the database the corresponding sign video, gathers those items using image management tools and reproduces the final set as a phrase in the LSM.

The system also considers expressions in Spanish that have more than one word while the LSM only has a single sign to represent it. The database contains a catalogue with around one hundred items having this feature. 


\section{$5 \quad$ Experiments}

The experiments were conducted in collaboration with the House of Culture of the deaf in the Cuauhtémoc District of the Mexico City. The center of attention has 4 teachers including two listeners. The tasks were performed by one of the not listeners' teachers.

It was requested to perform the translation of written sentences in Spanish into LSM. In total, 150 sentences were translated, 10 sentences for each structure were considered. We identified a set of 100 signs that can represent a complete sentence.

Sentences translated into LSM belong to any of the thirteen grammatical structures that the system recognizes as valid and which are referred to in previous sections. It was observed that when a deaf person does not know a sign that corresponds to a particular word, then he spells the unknown word.

At this moment, we conducting broader experiments, when the translation of the same set of sentences is made by 10 deaf persons, 5 of them are deaf persons who are literate and five more are deaf persons who are not literate. With this, we expect to find the differences between a Spanish translation into LSM with and without influence of the written Spanish.

At this moment, the system can perform the literal translation, i.e., it divides the sentence into words, the words are searched in the database of the system and are reproduced in the order they were found in the sentence.

Also, the system has a list of signs that correspond to particular statements. The corresponding module searches in the set of signs and if there exists a sign that corresponds to a full expression, it will be reproduced.

\section{Conclusions}

The following conclusions can be drawn:

- This paper presents a resource (dictionary) for automatic translation from written Spanish into LSM.

- We made several experiments for usage of the developed dictionary in the translation.

- The resources generated in this study are unique to the region of Mexico City and the metropolitan area, but they can be used also use in the rest of the country, maybe with certain adaptations.

The following more general considerations related to LSM were discovered during the work on the project:

- The mapping of the syntactic elements in written Spanish to LSM sentences requires, in most cases, a visual reference that associates the components in the proper context, for example, the prepositions of place.

- As all languages, LSM has several ways to map the syntactic structure of a sentence. One of these versions corresponds to sign Spanish. 
- During the work on this project, we found that the concept of regionalism in LSM may correspond both to the different geographical areas of a country and the local variations between what are called different "families". In case of Mexico City, there are at least three "families", each with variations in vocabulary and structure.

- LSM-related works have to specify the "family" or group of persons with whom they work.

- Unlike the ASL and LSF the government of Mexico does not have a unification project of vocabulary or structure of LSM.

- There are no sufficient corpora to achieve a good translation using the ruled based translation approach.

- We used the restrictions on sceneries and vocabulary to start working on the experiments on automatic translation into LSM.

\section{References}

1. Fridman-Mintz, B.: Reflexiones sobre las etnias sordas, Congreso iberoamericano de educación bilingüe para sordos, Paraguay (2012)

2. Maher, J., Sacks, O.: Seeing in Sign: The works of William Stokoe. Gallaudet University Press (1996)

3. Carreras, X., Chao, I., Padro, L., Padró, M.: Freeling: An Open-Source Suite of Language Analyzers. Proceedings of the 4th International Conference of Language Resources and Evaluation (LREC'04) (2004)

4. Serafín-Fleischman, M., González-Pérez, R.: Manos con voz, Diccionario de lengua de señas mexicana. Consejo Nacional para Prevenir la Discriminación (2011)

5. Lopez Garcia, L., Rodriguez, R., Cervantes, M., Zamora Martinez, S., San Esteban Sosa, S.: Mis manos que hablan, lengua de señas para sordos. Trillas (2013)

6. Calvo Hernández, M., Tamez Guerra, R.: Diccionario Español-Lengua de Señas Mexicana (DIELSEME), Estudio introductorio al léxico de la LSM. Secretaría de Educación Pública, Dirección de Educación Especial (2010)

7. Cruz-Aldrete, M.: Gramática de la Lengua de Señas Mexicana. Tesis de doctorado en lingüística, Centro de Estudios Lingüísticos y Literarios, El Colegio de México (2008)

8. TextoSign Herramienta software para la conversión de texto a lengua de signos. http://www.textosign.es/resumen_ejecutivo_textosign.pdf

9. Ibáñez, E., Huerta, A., San-Segundo,v R., D’Haro, L., Fernández, F., Barra, R.: Prototipo de traducción de voz a lengua de signos española. Universidad Politécnica de Madrid (2006)

10. Fundación Madrid para el Conocimiento: Catálogo de oferta tecnológica, servicios técnicos y programas de I+D. Tecnologías para la Sociedad de la Información. http://www.indracompany.com/sostenibilidad-e-innovacion/proyectosinnovacion/consignos-conversor-y-reproductor-automatico-de-len

11. Fundación para el Desarrollo de Herramientas Tecnológicas para Ayuda Humanitaria. http://www.hetah.net/ 